\title{
Chronic Non-Cancer Pain Management Capacity in Karachi
}

S. Fatima Lakha (D) - Peter Pennefather - Mubina Agboatwala •

Safia Zafar Siddique · Hanan E. Badr · Angela Mailis-Gagnon

Received: February 2, 2017 / Published online: May 29, 2017

(C) The Author(s) 2017. This article is an open access publication

\section{ABSTRACT}

Chronic non-cancer pain (CNCP) affects people everywhere in the world, but people in developing countries have far less access to therapies that provide relief. There are often missed opportunities to implement these therapies. Karachi shares many characteristics with megacities of the global south and represents Pakistan in the global city league. This review informs readers about the availability of health management and pain services for CNCP in Karachi, and their comparability to those found

Enhanced content To view enhanced content for this article go to http://www.medengine.com/Redeem/ 4128F0607F31D65C.

S. F. Lakha $(\bowtie) \cdot$ P. Pennefather · A. Mailis-Gagnon University of Toronto, Toronto, Canada

e-mail: sfatima.lakha@utoronto.ca

S. F. Lakha · P. Pennefather · A. Mailis-Gagnon Centre for Study of Pain, University of Toronto, Toronto, Canada

S. F. Lakha - A. Mailis-Gagnon

Pain and Wellness Center, Toronto, Canada

M. Agboatwala

HOPE, Karachi, Pakistan

S. Z. Siddique

Civil Hospital, Karachi, Pakistan

H. E. Badr

Kuwait University, Kuwait, Kuwait in other global cities. The literature about CNCP and its management in Karachi and Pakistan is scarce. Nevertheless, some conclusions can be made. In order to inform readers based in other global cities, a brief review of the current health system and pain services in Karachi and Pakistan are discussed together with barriers that impede pain service outputs. The present review employs vignettes to illustrate typical experiences of CNCP patients seeking pain management services in three sectors: public, charitable, and private institutions.

Keywords: Barriers; Chronic non-cancer pain; Global cities; Pain management and services

\section{INTRODUCTION}

Chronic non-cancer pain (CNCP) refers to pain of nonmalignant etiology that lasts for more than 3 months. It is widely regarded as a biopsychosocial disorder [1] that requires recognition of its multidimensional nature for effective patient-centered clinical management [2]. The chronic disease model suggests that the societal and personal burdens of such disorders can be more effectively treated through coordination of care where patients are actively engaged in implementing personalized multidimensional treatment strategies [3]. The lack of coordination and access to proven therapies 
encountered in developing countries increases the burdens of such problems. Indeed, a recent study indicates that disabling CNCP is more prevalent in developing countries [4], and that this high prevalence seems to be attributed to the limited treatment options and limited access to chronic pain management services in such countries.

In a developing country such as Pakistan, CNCP management services are not prioritized as clinical services because of many other competing concerns. As a result, even simple forms of pain management are often absent [5]. Systematic information regarding the prevalence and management of CNCP in Pakistan are not available. Even when patients do access health care services, pain relief remains elusive [6]. Several national and international associations have recognized this situation as a global health challenge and are collaborating to encourage global solutions [6, 7].

Cities ranked as global or world cities are recognized as important nodes in the global economy. They share common attributes such as access to the latest innovations and worldclass human and technical resources. These resources include high-quality health services staffed with practitioners trained at highly ranked educational centers. However, in a rapidly urbanizing world, world cities of the global south share a more pronounced burden of noncommunicable diseases, including pain [8]. This review examines the case of CNCP management in Karachi, Pakistan's global city, and explores how those services might be more comparable to those found in other global cities. Developing advanced clinical services such as CNCP management facilities can be as effective as building hospitals for promoting health and wellbeing. Reducing the burden of $\mathrm{CNCP}$ can be rationalized from both ethical and economical perspectives. Documenting the landscape of CNCP management services will provide a useful lens for evaluating best practices and barriers to health system development.

In order to understand the landscape of pain management and services available in Karachi with respect to global cities, there is a need to first review the current federal health system in which the city system functions. This review then explores structural factors that act as determinants of pain management service availability in Karachi, as well as barriers that impede the implementation of global best practices. The present review also uses the lens of three patient personas interacting with different sectors of the Karachi health care system: public, private, and charitable. A comprehensive electronic literature search (1960-2015) was performed using key words ("chronic non-cancer pain," "chronic pain patient," "Pakistan," "Karachi," "developing countries," "musculoskeletal pain," "neuropathic pain," "causes," "prevalence," "pain management," "pain therapies," and "treatment for pain") in multiple databases (Medline, Science Direct, Scholars Portal, Sociological, CINAHL, and Google Scholar). In addition, official reports published in English were also reviewed. Statistical data were obtained from the website of the Federal Bureau of Statistics, Pakistan. Gray literature and references cited in relevant articles were also reviewed. This comprehensive literature search provided evidence on pain management services in Karachi, Pakistan and is summarized in this manuscript. The purpose of this review is to assess the current status of CNCP management practices in Karachi (and Pakistan in general) and to highlight opportunities for ongoing development. The results of this review are presented using a combination of case study [9], illustrative vignettes [10], and narrative review [11].

\section{Compliance with Ethics Guidelines}

This review article is based on previously conducted studies and does not involve any new studies of human or animal subjects performed by any of the authors.

\section{GENERAL BACKGROUND ABOUT PAKISTAN}

Pakistan is the world's sixth most populous country, with a population of over 180 million, and it has one of the highest population growth 
rates in the world [12]. It is estimated that $24 \%$ of the population lives below the poverty line [13]. About $2.8 \%$ of its gross domestic product (GDP) is spent on health care, which is lower than that of any other neighboring developing country [14]. The bulk of that expenditure is directed towards supporting tertiary healthcare, which is accessed by only about $15 \%$ of the population. Only $15 \%$ of the total health care budget (less than $0.4 \%$ of GDP) is spent on primary health care [15]. An increasing proportion of Pakistan's population (38\%) lives in an urban setting [14]. Around 13\% of its population, or 24 million people, live in Karachi.

As Pakistan undergoes economic development, changing lifestyles have resulted in a growing burden of non-communicable diseases (NCDs). Deaths due to NCDs now far outnumber deaths due to communicable diseases [16]. This is relevant because the burden of many of these NCDs is increased by CNCP symptoms associated with them [17].

\section{PAKISTAN'S NATIONAL HEALTH SYSTEM}

\section{Current Status of Health and Pain Services in Pakistan}

Most provincial governments are primarily responsible for health care management in Pakistan. Every provincial government has a department of health that serves to protect the health of its population by providing basic health care amenities. There is a divide in spending on health care in the public sectors across the provinces. The formulation of national health policies falls under the jurisdiction of the federal government [14]. There is a three-tiered system in which public, private, and nongovernmental sectors participate in the provision of health care in Pakistan.

Public health care is subsidized to make it accessible to most residents by offering it at a low cost. Patients that are treated in an outpatient department (OPD) of a public hospital do not have to pay for the consultations, but they do when buying prescribed medicines or other health products and services. In contrast, private health care is primarily a fee-for-service system and covers a range of health care provisions [18]. Despite considerable advances in recent years, a lack of trained health care professionals and basic health system infrastructure, especially with regards to physical medicine and rehabilitation, is recognized as an important limiting factor for more effective CNCP care in Pakistan [5]. No government-sponsored health insurance plan is available in Karachi, but private health insurance is available for the few who can afford it. Most of the population cannot afford to access the health care system directly. To meet this need, several private charity hospitals have emerged to provide free, high-quality health care, including pain management services [19].

In Pakistan, $79 \%$ of the population utilizes some aspects of the private health sector [18]. In the private sector, there are some accredited facilities and hospitals, but also many unregulated hospitals, nonmedical general practitioners, hakeems, traditional/spiritual healers, Unani (Greco-Arab) healers, herbalists, and bonesetters [20]. There are no formal watchdog bodies, agencies, or audit commissions set up to monitor the quality of health care delivered to patients [21]. A recent study revealed that between 1990 and 2013, years lost to disability from musculoskeletal disorders increased by $163 \%$ among women in Pakistan [22]. Lack of quality care is an issue for all chronic illnesses, and CNCP is a significant health problem that is commonly presented by patients suffering from complex chronic conditions [23].

Currently, there are very few established pain clinics, despite the introduction of pain medicine as a specialty in the mid-1980s in Pakistan. Recently, health experts have expressed concern over the absence of acute, chronic, cancer, and childbirth pain relief services in the majority of public and private hospitals in all provinces [24].

Unrelieved pain remains a national health problem; however, reliable data regarding the prevalence and incidence of chronic pain are limited. To illustrate the scale of the problem from existing data, information from a WHO collaborative study of pain in primary care [25] revealed that chronic pain was present in 
approximately $5-33 \%$ of individuals in any global city. As Karachi is the major global city of Pakistan, investment in pain management facilities could have an important impact on its citizens' wellbeing while stimulating health system development towards global standards.

\section{Karachi}

Karachi is the capital of the province of Sindh; it is the largest and most populous metropolitan city of Pakistan as well as its main seaport and the financial center of the country. The metro region of Karachi had an estimated population of over 23.5 million as of 2013 [26]. It is also ranked as a beta global city [27]. There are currently about 4700 Katchi abadis (squatter settlements) which provide housing to $55 \%$ of the residents of Karachi [28]. The populations of these Katch abadis experience poor living and health conditions and very limited access to healthcare services [8].

\section{Health Care Services in Karachi}

Healthcare in Karachi is administered by both private and public health care providers (integrated healthcare). The Sindh province (including Karachi) ranks lowest for public sector healthcare facilities; only $22 \%$ of its population uses these facilities, in comparison to $29 \%$ in the rest of Pakistan. Thus, $78 \%$ of the population of Karachi use private practitioners, whereas this figure is $71 \%$ for the rest of the country [29]. On average, there is one doctor to every 1206 patients. There are 134 private and public hospitals with total bed strength of 21,170 to cover the population of 20 million in Karachi. Public sector hospital beds account for 11,550 while the private sector has 9520 hospital beds [30]. According to a government report, rural areas have well-designed district health systems but they are functioning poorly, while urban areas have "an almost nonexistent primary and secondary health care tier." Thus, the few tertiary hospitals get utilized beyond capacity. In Karachi, the three large government hospitals are overwhelmed by the demands of 20 million people. Government statistics indicate that the percentage of GDP allocated to health care declined from $0.7 \%$ in the fiscal year $2000-01$ to $0.3 \%$ in the fiscal year $2010-11$ $[29,31]$. As a result, the majority of the poor population of the city must pay privately to get access to any health service, including pain management.

\section{Significance of Chronic Pain in Karachi}

Chronic pain is an important health issue in the adult population of Karachi and Pakistan [32, 33]. Recently, two studies conducted in public and private academic teaching hospitals in Karachi revealed a prevalence of chronic non-cancer pain that did not discriminate between the sexes (the female/male ratio was 1:0.9). Musculoskeletal problems were the predominant cause of pain, and the most common complaint was low back pain. Two abstracts provide interesting comparative information concerning a private [32] and a public [33] hospital. The public teaching hospital was visited by a younger demographic and its patients ranked their pain higher on a numerical rating scale (NRS) of pain than the patients at the private academic teaching hospital, which tended to have an older patient population. Another survey revealed that most general practitioners (GPs) (85\%) lacked knowledge about modern methods of relieving pain, especially interventional pain techniques. Also, the survey indicated that nearly half of the GPs were unaware of the existence of pain clinics and pain physicians [34].

Despite the undisputed fact that there is a high prevalence of chronic pain at the national and international level, there remains a lack of scientific evidence pertaining to the precise prevalence of and the types of management services offered for CNCP in Karachi and Pakistan.

\section{Pain Services in Karachi}

In Karachi, the idea of "pain management"especially through the agency of a specialized "pain clinic"-is an evolving concept, and very few institutions offer these services. The first multidisciplinary pain clinic to be established has been run by Aga Khan University 
Hospital, Karachi since 1998 [32]. CNCP management is primarily regarded as an anesthesia subspecialty, though experts from other disciplines are also involved. Currently, there are only two government hospitals and three private hospitals that have pain management clinics in Karachi. The directors and clinicians at those clinics are primarily anesthesiologists (S. Zafar, personal communication, Oct 2015).

The geographical distributions of the clinics are unplanned and are not designed for maximum benefit by the general population of Karachi. There is a dearth of information concerning how people who suffer from chronic pain are gaining access to adequate pain treatment. Also, there is a lack of awareness, particularly among primary health care physicians, about the presence of pain clinics in Karachi. Therefore, the majority of these general physicians provide CNCP management to complex patients without having any specialization in the subject and do not refer them to a pain specialist. In comparison to private hospitals, very few public hospitals have pain clinics in Karachi [31]. Private sector clinics are very expensive. Therefore, many pain patients in Karachi seek pain treatment from traditional healers (hakims and "pehlwans") for pragmatic as well as for cultural and economic reasons [35].

In addition, many patients visit informal healthcare practitioners (HCPs), physiotherapists, and occupational therapists for their ongoing pain. Hospitals in Karachi do not follow the multidisciplinary approach for CNCP and rehabilitation recommended by international bodies [8]. As a result, allied health professionals are often unaware of pain clinics and therefore deal with their patients' pain independently of those clinics. This is particularly true of the pain management services provided by physiotherapists working independently in the private sector or running physiotherapy departments in government hospitals. Provisions must be made to transform the delivery of chronic pain services into an integrated system through improved coordination and communication between various healthcare sectors and professions.
At a recent conference, a Pakistani anesthesiologist mentioned that while morphine and other opioid analgesics had crucial roles to play in all kinds of chronic pain management, they were not available in hospitals. The reason for this was said to be the time-consuming procedure involved in procuring drugs for hospitals and patients. A global study by the Global Opioid Policy Initiative reveals a pandemic of unbearable pain affecting billions, caused by the overregulation of opioids and morphine [36]. However, there is no specific study relating to opioid availability and accessibility for CNCP. Patients are usually given injections in the clinics to manage acute pain with opioids. This is true even though morphine injection can be substituted with oral dosages of morphine, which are cost-effective, safer, and as effective for pain relief. Indeed, the World Health Organization recommends oral administration for $\mathrm{CNCP}$, if possible. There is a need to create awareness among both clinicians and the general public about the optimal use of these analgesics [24].

Globally, Pakistan is one of the countries with the highest rates of injection usage [37]. In comparison to the national level, the use of injections in Karachi is $13 \%$ higher [38]. Relief from severe pain is an important reason for injection therapy, as many patients are unable to tolerate pain and consider injections to be the only form of treatment that provides immediate relief [39].

In 2014, the College of Physicians and Surgeons Pakistan (FCPS) approved specialization in pain management as a subspecialty of anesthesia. This is a first step in the development of this important field in Pakistan [24]. Aga Khan University Hospital offers a fellowship in pain management to the anesthesiologist after their successful completion of the anesthesia residency program [34]. A private medical university in Islamabad offers a Master's program in pain management for anesthesiologists only, and many anesthesiologists from Karachi enroll themselves in it (S. Zafar, personal communication, Oct 2015). Key informants acknowledge that pain management training remains inadequate in medical schools across Karachi. In particular, graduates entering clinical practices 
are inadequately trained in interprofessional collaboration for pain management.

Recently, a group of anesthesiologists, with IASP support, delivered courses on "pain education and services" to family physicians in several cities [40, 41]. The researchers who organized these educational activities in Pakistan are from Karachi. CNCP education and delivery of management services seems to be better in Karachi than in the rest of Pakistan. However, there are no available reports on the impact of those workshops. Many private and public hospitals conduct pain awareness programs and workshops for patients, general practitioners, and residents throughout the year (S. Zafar, personal communication, Oct 2015). However, those pain management programs are delivered in an ad hoc manner and are not staged strategically to reach a wider population.

Given the complex nature of the healthcare delivery system in Karachi and the limited resources available for the management of $\mathrm{CNCP}$, it is instructive to illustrate how existing CNCP services are offered by different health sectors in Karachi using hypothetical vignettes based on our review.

\section{Vignettes}

The interactions of health professional with patients are complex, and occur in an ad hoc manner. There is likely to be a lack of coordination in the interaction between patient, health professional, and institution. This contributes to undertreatment of chronic pain and missed opportunities to reduce the CNCP burden. The present review uses a clinical vignette approach to illustrate expectations of how the care received by $\mathrm{CNCP}$ patients within the three main health sectors (private, public, and charitable organizations) could impact the outputs of services provided by pain clinics. Vignettes are standardized case studies that are not fully realistic but are comparable across clinicians and can be used for most outpatient conditions. The goal of the use of vignettes in our review is to illustrate how common conditions are likely to be dealt with in a setting that is typical of the sector, while allowing comparison across sectors. The following vignettes are adapted with input from key informants from Pakistan, from treatment program cases, which provide a glimpse into patients' experiences (Table 1) (at http://www.kktpakistan.com/ patient-testimonials/back-pain/).

As noted in the vignettes, all patients-regardless of the health sector-are likely to be treated at a single-modality pain clinic. Long-lasting pain results in profound changes in pain perception, pain threshold, coping mechanism, mood, and enjoyment of social and professional life [3]. Due to the complexity of chronic pain, no single discipline has the expertise to assess and manage it independently. A multidisciplinary team approach is considered to be the optimal therapeutic model for CNCP patients [42]. To ensure that care is delivered in a coordinated manner, clinicians should familiarize themselves with evidence-based treatment guidelines. In order to improve pain management and maximize their patients' quality of life, clinicians should use treatment and clinical activities that suit the needs of the patient [43]. However, existing literature supports the perspective provided by the vignettes: that most clinics offer only a monotherapeutic rather than a comprehensive multidisciplinary approach in Karachi [5].

Vignettes make an important contribution to knowledge because they allow some understanding of the distribution of proficiency in the different health sectors. When developing strategies and management skills for chronic pain, the barriers that hinder progress in $\mathrm{CNCP}$ management in Karachi must be taken into consideration.

\section{Barriers}

There are many systemic factors related to the healthcare system, healthcare professionals, and healthcare users that contribute to the burden of unrelieved pain. Many of those factors are the same as those that were considered to require urgent attention 20 years ago in developed countries [44]. Also, the lack of chronic pain management options for 
Table 1 Patient vignettes

\begin{tabular}{|c|c|}
\hline $\begin{array}{l}\text { Case } 1 \\
\text { Pakistan national }\end{array}$ & $\begin{array}{l}\text { Case } 2 \\
\text { Pakistan national }\end{array}$ \\
\hline Private system & Charitable system \\
\hline Mr. X, 29 years & Mr. Y, 29 years \\
\hline $\begin{array}{l}\text { Present complaint: Suffered low back } \\
\text { pain } 6 \text { years previously after slipping } \\
\text { at work as a manager; unable to work } \\
\text { since. Gradually developed an } \\
\text { antalgic gait and spreading pain to his } \\
\text { upper thigh, knees, wrists, and ankles }\end{array}$ & $\begin{array}{l}\text { Present complaint: Suffered low back } \\
\text { pain } 6 \text { years previously after slipping } \\
\text { at work as a painter; unable to work } \\
\text { since. Gradually developed spreading } \\
\text { pain to his upper back, knees, and } \\
\text { wrists }\end{array}$ \\
\hline $\begin{array}{l}\text { Associated complaints: Fragmented } \\
\text { sleep, weight gain, depression, very } \\
\text { high disability }\end{array}$ & $\begin{array}{l}\text { Associated complaints : Fragmented } \\
\text { sleep, weight gain, very high disability }\end{array}$ \\
\hline $\begin{array}{l}\text { Medical and psychosocial history: } \\
\text { Investigations showed minimal } \\
\text { findings that did not explain the } \\
\text { multi-site pain and level of disability. } \\
\text { Failed conservative pain } \\
\text { management. Discontinued a } \\
\text { retraining course due to worsening } \\
\text { low back pain }\end{array}$ & $\begin{array}{l}\text { Medical and psychosocial history: three } \\
\text { back surgeries, but the last two failed } \\
\text { to provide him with any pain relief. } \\
\text { On medication for at least } 7.5 \text { years, } \\
\text { with intermittent epidural injections } \\
\text { for the last year. Has stopped } \\
\text { working full-time, but continues to } \\
\text { perform irregular part-time work. Is } \\
\text { currently managing the pain with } \\
\text { pain medication }\end{array}$ \\
\hline
\end{tabular}

Case 3

Pakistan national

Public system

Mr. Z, 29 years

Present complaint: Suffered low back pain 6 years previously after slipping at work as a painter; unable to work since. Gradually developed spreading pain to his upper back and knees

Associated complaints: Fragmented sleep, mood with periods of irritability, and very high disability

Medical and psychosocial history: Disabling LBP with radicular symptoms in right leg. Initially stopped working for 6 weeks. Attended and passed a functional capacity evaluation. Attempted to return to work. This failed due to increasing and intolerable pain after the third day. One year has passed since that attempt. Wants to avoid intervention and prescribed medication because of financial constraints and limited insurance. Radiology shows an extruded disc herniation at L5-S1 that could be corrected surgically

Assessment: O/E looks , sweaty,
Assessment: $\mathrm{O} / \mathrm{E}$ is an overweight deconditioned man who dozed off constantly but sat comfortably during most of the interview despite a pain rating of $8 / 10$
Assessment: O/E looks despondent and exhibits verbal and nonverbal pain behaviors; rated pain 13/10. His gait is normal, although he intermittently appears antalgic, favoring the right leg. Able to stand on his heels and toes but has only a squat capacity of only $50 \%$ due to weakness in the left leg 
Table 1 continued

\begin{tabular}{|c|c|c|}
\hline $\begin{array}{l}\text { Case } 1 \\
\text { Pakistan national }\end{array}$ & $\begin{array}{l}\text { Case } 2 \\
\text { Pakistan national }\end{array}$ & $\begin{array}{l}\text { Case } 3 \\
\text { Pakistan national }\end{array}$ \\
\hline $\begin{array}{l}\text { Expected outcome: Prescribed } \\
\text { long-term pharmacotherapy without } \\
\text { any benefit. Despite being treated at a } \\
\text { private hospital with full access to } \\
\text { health care, pain ratings remain high } \\
\text { and still exhibits extreme disability. } \\
\text { Morbidly depressed, which is not well } \\
\text { addressed, and pain is not being } \\
\text { relieved }\end{array}$ & $\begin{array}{l}\text { Expected outcome: Interventions and } \\
\text { medications have provided partial } \\
\text { pain relief, though he continues to } \\
\text { experience persistent pain and partial } \\
\text { disability. }\end{array}$ & $\begin{array}{l}\text { Expected outcome: His interventions } \\
\text { and medications have provided him } \\
\text { with partial pain relief though he } \\
\text { continues to experience persistent } \\
\text { pain and disability. As he was treated } \\
\text { at a public hospital, he has limited } \\
\text { access to health plans, so pain } \\
\text { remains unrelieved }\end{array}$ \\
\hline
\end{tabular}

marginalized and special populations (children and the elderly) within countries raises significant health equity concerns. These factors continue to limit access to CNCP management in both developed and developing heath systems [45-47]. After reviewing the literature on rehabilitation and pain management services in Karachi and Pakistan, various important barriers to pain assessment and the recommended adherence to treatment regimens [5, 24, 48] were identified, as shown in Table 2.

Thus, the pain management crisis that results from these systematic barriers must be resolved to improve CNCP management. Identifying and acknowledging these barriers is a first step to overcoming them. Successful initiatives to overcome patient, physician, and institutional barriers need to be multidimensional and integrative. Key informants suggest that the need and the opportunity to invest in pain management services in Pakistan are starting to be recognized (S. Zafar, personal communication, Oct 2015).

\section{OPPORTUNITIES FOR CHRONIC PAIN MANAGEMENT IN KARACHI}

The expression of chronic pain in different individuals in different locations and its impact on their quality of life varies greatly in type, intensity, frequency, and prognosis. The goal of pain treatment is not to cure disease but to improve quality of life and allow the CNCP patient to function as effectively as possible. However, resources and patient demands vary throughout the world, and international guidelines need to be adapted to local realities. The strategies and information presented in this review are offered as a guide for clinicians, educators, administrators, and governmental or professional organizations involved in the establishment and maintenance of standards for pain treatment services in urban settings in Pakistan (Fig. 1). However, they may have relevance to other global city settings. The suggested recommendations are the synthesis of the current literature, and are presented here to aid attempts to improve pain management services and facilities, including those in resource-limited settings $[1,2,24,49-52]$. These recommendations are not intended to represent required standards. Rather, it is recognized that these idealized practices will need to be adapted to the needs and constraints of the health system in Karachi and Pakistan (Fig. 1).

\section{Summary of Recommendations}

(1) Increasing availability and accessibility of chronic pain management services across the city of Karachi, based on the guideline provided by the WHO policy for pain management, should be considered a strategic investment in urban development.

(2) There is a need to invest in infrastructure and access to systematized services such as rehabilitative services, behavioral medicine, and medications so as to enhance 
Table 2 Barriers to effective chronic non-cancer pain

Healthcare professional barriers

Healthcare user barriers

Healthcare system barriers
Inadequate knowledge of treatment options

Inaccurate evaluation of pain

Legal issues regarding substances

Concerns about addiction

Fear of respiratory depression

Pharmacologic tolerance

Pain management is a low priority

Cultural or social barriers

Inadequate reimbursement for physicians

Under-reporting pain

Fear that the disease is worsening

Shifting focus from the disease

Fear of addiction

Fear of being identified as an addict

Poor compliance

Reliance on traditional medicine

Cultural/social/religious barriers

Limited specialist or treatment access

Formulary limitations

Lack of or limited availability of opioids (quantity)

Restrictions on inventory systems

Pain management is a low priority

Regulatory requirements/restrictive regulations treatment of $\mathrm{CNCP}$ at a primary care provider level, as per patient needs.

(3) For more complex cases, if primary services prove inadequate, more specialized assessment services that apply a coordinated multidisciplinary approach need to be accessed, and ongoing care needs to be integrated and coordinated in a comprehensive manner. All healthcare professionals could benefit from professional development around providing comprehensive CNCP services at all levels of the health care system.
(4) A rigorous curriculum focusing on pain education should be introduced at the undergraduate level in medical schools, and interfaculty and interprofessional short courses should be encouraged. Chronic pain patients also need to be viewed as part of the solution; they also require education about pain, including instruction in self-management strategies.

(5) The quality of care delivery and outcomes associated with chronic pain management services should be analyzed systematically. These data can then be used to raise 


\section{Opportunities for Pain Management Practice Development in Karachi}

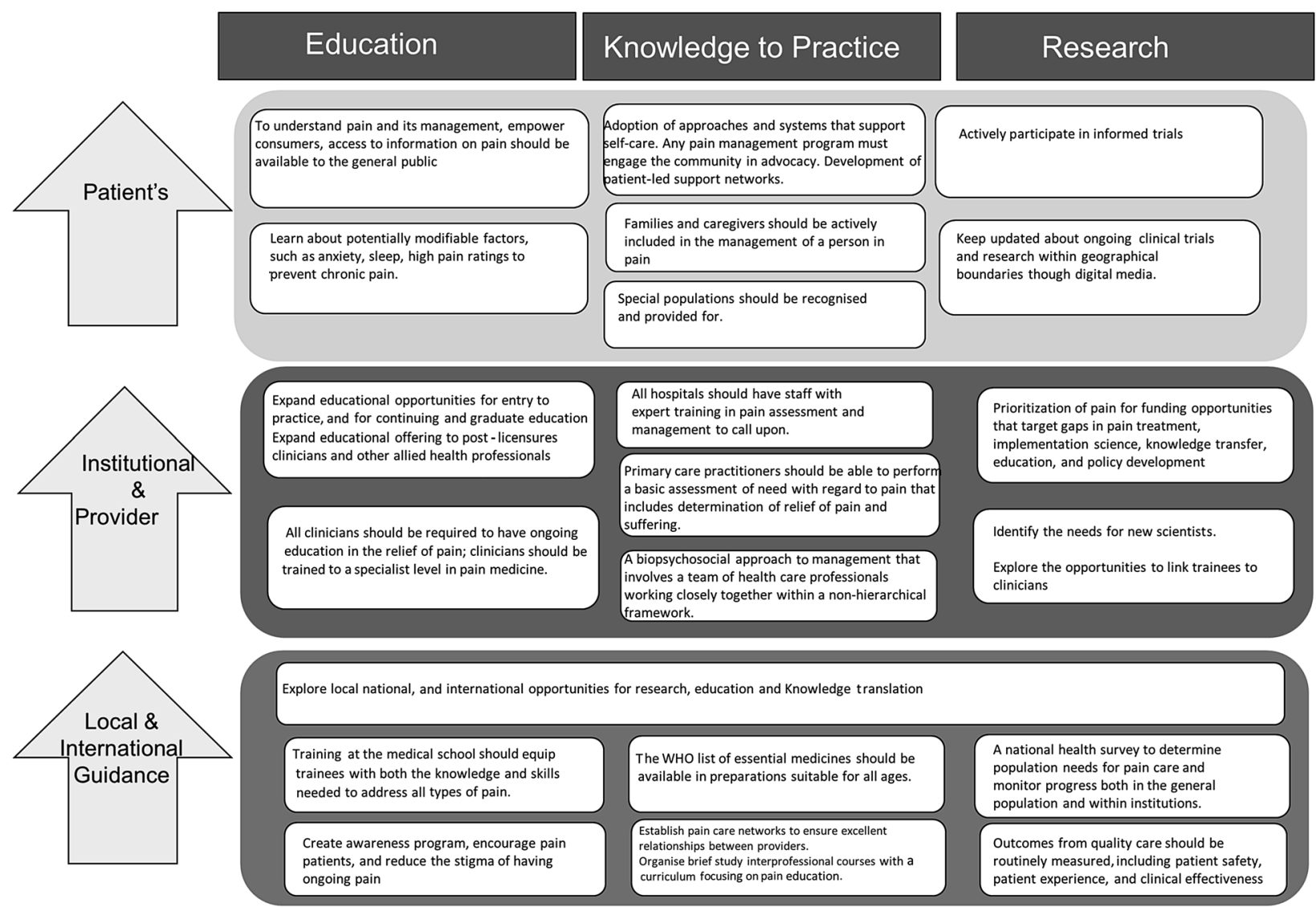

Fig. 1 Schematic presentation of recommendations

awareness in public and primary care providers about the importance of seeking CNCP healthcare services.

(6) Barriers that hinder people with special needs (e.g., children, older adults, the developmentally challenged, the cognitively impaired) from receiving $\mathrm{CNCP}$ assessment and management need to be addressed.

\section{CONCLUSION}

The challenges facing CNCP management in Karachi are numerous and multifaceted. The health system consists of charitable, public, and private sectors, with most of health services provided by a loosely coordinated private sector. Planning for the future in relation to pain management in Karachi is becoming extremely difficult due to the large number of patients, insufficient data, the lack of infrastructure, the scarcity of trained professionals, and the lack of a venue for coordinating efforts to improve the quality of care across the system and for sharing data pertaining to such efforts. Although a culture of ongoing research, reflection, and improvement is developing slowly, this progress could be accelerated by embracing better CNCP management as a civic goal. This review has demonstrated that there is a need for and an opportunity to improve the education of health care providers and patients regarding CNCP management and to enhance the involvement of government, educational, and professional society institutional actors in advancing internationally recognized CNCP practice standards $[1,2]$. The first step in that regard would be to 
explore mechanisms for improving access to and the appropriate use of pain management drugs as well as to create dedicated facilities for chronic pain management services at all public and private sector hospitals. As the first item of business, such facilities could be charged with evaluating the need for pain management drugs and ensuring that these drugs are used appropriately within the framework of a comprehensive CNCP management plan. Adapting international standards for dealing with the universal problem of CNCP management to the complex but localized context of the global city of Karachi could trigger innovative thinking concerning health services with potentially far-reaching consequences.

\section{ACKNOWLEDGEMENTS}

No funding or sponsorship was received for this study or the publication of this article. All named authors meet the International Committee of Medical Journal Editors (ICMJE) criteria for authorship for this manuscript, take responsibility for the integrity of the work as a whole, and have given final approval for the version to be published. I would like to thank Sunita Kak (who was not provided with any financial assistance) for her editorial assistance with this manuscript.

Disclosures. S. Fatima Lakha, Peter Pennefather, Mubina Agboatwala, Safia Zafar Siddique, Hanan E. Badr, and Angela Mailis-Gagnon have nothing to disclose.

Compliance with Ethics Guidelines. This review article is based on previously conducted studies and does not involve any new studies of human or animal subjects performed by any of the authors.

Open Access. This article is distributed under the terms of the Creative Commons Attribution-NonCommercial 4.0 International License (http://creativecommons.org/licenses/ by-nc/4.0/), which permits any noncommercial use, distribution, and reproduction in any medium, provided you give appropriate credit to the original author(s) and the source, provide a link to the Creative Commons license, and indicate if changes were made.

\section{REFERENCES}

1. Breivik H, Eisenberg E, O'Brien T. Open-minds. The individual and societal burden of chronic pain in Europe: the case for strategic prioritization and action to improve knowledge and availability of appropriate care. BMC Public Health. 2013;13:1229.

2. Fishman SM, Young HM, Lucas Arwood E, Chou R, Herr K. Core competencies for pain management: results of an inter-professional consensus summit. Pain Med. 2013;14:971-81.

3. Coleman K, Austin BT, Brach C, Wagner EH. Evidence on the chronic care model in the new millennium. Health Aff (Millwood). 2009;28:75-85.

4. Johnson MI, Elzahaf RA, Tashani OA. The prevalence of chronic pain in developing countries. Pain Manag. 2013;3:86.

5. Rathore FA, New PW, Iftikhar A. A report on disability and rehabilitation medicine in Pakistan: past, present, and future directions. Arch Phys Med Rehabil. 2011;92:161-6.

6. American Cancer Society. Treat the Pain: a country snapshot, Pakistan. 2015. http://www.treatthepain. org/Assets/CountryReports/Pakistan.pdf.

7. Bond $\mathrm{M}$, Breivik $\mathrm{H}$. Why pain control matters in a world full of killer diseases. Pain Clin Updates. 2004;12(4):1-4.

8. Gayer L. Karachi: ordered disorder and the struggle for the city. New Delhi: Hurst \& Co.; 2015.

9. McLeod SA. Case study method. 2008. www. simplypsychology.org/case-study.html.

10. Evans SC, Roberts MC, Keeley JW, et al. Vignette methodologies for studying clinicians' decision-making: validity, utility, and application in ICD-11 field studies. Int J Clin Health Psychol. 2015;15:160-70.

11. Green BN, Johnson CD, Adams A. Writing narrative literature reviews for peer-reviewed journals: secrets of the trade. J Chiropr Med. 2006;5:101-17.

12. Amer K. Population explosion: put an embargo on industrialization in Karachi. The Express Tribune. 6 Oct 2013. http://tribune.com.pk/story/614409/ 
population-explosion-put-an-embargo-on-industrialisation-in-karachi/. Accessed 25 August 2015.

13. Faridi MZ, Nazar R. Impact of fiscal autonomy on poverty in Pakistan. Pak J Commer Soc Sci. 2013;7:141-56.

14. The Pakistan Bureau of Statistics. Website. http:// www.pbs.gov.pk/. Accessed Feb 2016.

15. Khan SI. Youth and the millennium development goals in Pakistan. Peace Confl Monit. 2011;3.

16. Jafar TH, Haaland BA, Rahman A, et al. Non-communicable diseases and injuries in Pakistan: strategic priorities. Lancet. 2013;381:2281-90.

17. FDI. Policy statement on non-communicable diseases. Adopted by the FDI General Assembly on August 2012, Hong Kong. 2012. http://www. fdiworldental.org/media/11291/Non-communicable \%20diseases-2012.pdf. Accessed August 2015.

18. Akbari AH, Rankaduwa W, Kiani AK. Demand for public health care in Pakistan. Pakis Dev Rev. 2009;48(2):141-53.

19. Noorani A. Well done Pakistanis! The Dawn Newspaper. 9 July 2011. https://www.dawn.com/news/ 642718.

20. Shaikh BT. Private sector in health care delivery: a reality and a challenge in Pakistan. J Ayub Med Coll Abbottabad. 2015;27:496-8.

21. Anwar S. Health care delivery in Karachi-the worst of both worlds. Health Care. 2008;58:595-6.

22. Lim SS, Vos T, Flaxman AD, Danaei G, Shibuya K, Adair-Rohani H. A comparative risk assessment of burden of disease and injury attributable to 67 risk factors and risk factor clusters in 21 regions, 1990-2010: a systematic analysis for the Global Burden of Disease Study 2010. Lancet. 2013;380: 2224-60.

23. Tunstall-Pedoe H. Preventing chronic diseases. a vital investment: WHO Global Report. Int J Epidemiol. 2006:35; 4:1107-1107. ISBN 9241563001. http://www.who.int/chp/chronic_disease_report/ en/.

24. Anon. All pain, no gain: health experts express concern over lack of pain relief services. The Express Tribune. 23 Mar 2014. http://tribune.com.pk/story/ 686136/all-pain-no-gain-health-experts-expressconcern-over-lack-of-pain-relief-services/.

25. Gureje O, Von Korff M, Simon GE, Gater R. Persistent pain and well-being: a WHO study in primary care. JAMA. 1998;280:147-51.
26. Pakistan Ministry of Finance. Pakistan economic survey 2013-14: population, labour force and employment report. http://www.finance.gov.pk/ survey/chapters_14/12_Population.pdf. Accessed August 2015.

27. PWC. The World According to GaWC 2012: Global city GDP rankings 2008-2025. http://www.lboro.ac. uk/gawc/world2012t.html. Accessed August 2015.

28. Rind HM. Katchi Abadis house half of Karachi's population. The News (International Print Edition). 15 Nov 2013. http://www.thenews.com.pk/TodaysNews-3-214351-Katchi-Abadis-house-half-of-Karachispopulation.

29. Akram M, Khan F. Health care services and government spending in Pakistan (PIDE Working Paper 2007: 32). Islamabad: Pakistan Institute of Development Economics; 2007. http://workspace.unpan. org/sites/internet/Documents/UNPAN93997.pdf.

30. Anon. Clinical proceedings of SURGICON 2013: only $20-25 \%$ hospitals in Karachi have proper ICUs and $50 \%$ have monitoring facilities. Pulse Int. 1 Feb 2014. http://www.pulsepakistan.com/index.php/ main-news-feb-1-14/632-only-20-25-hospitals-inkarachi-have-proper-icus-and-50-have-monitoringfacilities-prof-tipu-sultan.

31. Anon. Lack of healthcare provisions in a disease-stricken land. The Dawn Newspaper. 27 June 2012. http://www.dawn.com/news/729890/lack-ofhealthcare-provisions-in-a-disease-stricken-land. Accessed August 2015.

32. Afshan G. Pain characteristics and demographics of patients attending tertiary care hospital based pain clinic, Aga Khan University Karachi, Pakistan (abstract from First National Research Symposium on Anaesthesia, Pain and Critical Care, AKUH Karachi, 3-4 March 2012). APIC. 2012. http://www. apicareonline.com/?p=1132.

33. Sarwar S, Iqbal MK, Arif MA, Haider S. Demographic and pain characteristics of patients attending a public hospital pain management clinic in Karachi, Pakistan. Abstract from 14th World Congress on Pain (IASP 2012); 2012 Aug 27-31; Milan, Italy.

34. Afshan G, Hussain AM, Azam SI. Knowledge about pain clinics and pain physician among general practitioners: a cross-sectional survey. Pain Ther. 2013;2(2):105-11.

35. Mohyuddin A, Ambreen M. From faith healer to a medical doctor: creating biomedical hegemony. Open J Appl Sci. 2014;4:56-67.

36. Cleary J, Silbermann M, Scholten W, Radbruch L, Torode J, Cherny NI. Formulary availability and 
regulatory barriers to accessibility of opioids for cancer pain in the Middle East: a report from the Global Opioid Policy Initiative (GOPI). Ann Oncol. 2013;24:951-9.

37. WHO. The world medicines situation. Geneva: World Health Organization; 2004. http://apps.who. int/medicinedocs/pdf/s6160e/s6160e.pdf.

38. Raglow GJ, Luby SP, Nabi N. Therapeutic injections in Pakistan: from the patients perspective. Trop Med Int Health. 2001;6:75.

39. Agboatwala M, Hutin Y, Luby S, Mussarat A. A pilot intervention to improve injection practices in the informal private sector in Karachi, Pakistan (abstract \#AC 112 from the Second International Conference on Improving Use of Medicines (ICIUM), Chiang Mai, Thailand, 2004). http://apps. who.int/medicinedocs/documents/s14078e/s1407 8e.pdf.

40. Anon. Pain education for family health care providers. NAYS e-Newslett. 2013;23. http://www.nays.com.pk/ wp-content/uploads/2012/05/NAYS-e-NewsletterJuly-August-2013-Issue-23.pdf.

41. Gauhar A, Robyna K, Aliya A, Naveed L, Mohammad Y, Tanveer B. Pain relief via education: first step towards improving pain management in developing countries. J Anesth Clin Res. 2015;6: 517-22.

42. Ospina M, Harstall C. Multidisciplinary pain programs for chronic pain: evidence from systematic reviews (HTA \#30). Edmonton: Alberta Heritage Foundation for Medical Research (AHFMR); 2003. http://www.ihe.ca/hta/publications.html. Accessed August 2015.

43. Loeser JD. Desirable characteristics for pain treatment facilities. Pain. 1990;41:S479.
44. Lohman D, Schleifer R, Amon JJ. Access to pain treatment as a human right. BMC Med. 2010;8:1-9.

45. Cherny NI, Baselga J, DeConno F, Radbruch L. Formulary availability and regulatory barriers to accessibility of opioids for cancer pain in Europe: a report from the ESMO/EAPC Opioid Policy Initiative. Ann Oncol. 2010;21:615-26.

46. Silbermann M, Arnaout M, Daher M, et al. Palliative cancer care in Middle Eastern countries: accomplishments and challenges. Ann Oncol. 2012;23:15-28.

47. Zuccaro SM, Vellucci R, Sarzi-Puttini P, Cherubino $\mathrm{P}$, Labianca R, Fornasari D. Barriers to pain management. Clin Drug Investig. 2012;1:1-9.

48. Hamid M, Gangwani AL, Akhtar MI. A quality improvement survey to assess pain management in cardiac surgery patients. Open J Anesthesiol. 2015;5:105-12.

49. American Society of Anesthesiologists Task Force on Chronic Pain Management, American Society of Regional Anesthesia and Pain Medicine. Practice guidelines for chronic pain management. Anesthesiology. 2010;112:810-33.

50. International Association for the Study of Pain. Annual report. 2011. http://www.iasp-pain.org/files/ Content/ContentFolders/AboutIASP/IASPAnnual Report2011.pdf.

51. Kopf A, Patel NB. Guide to pain management in low-resource settings. Seattle: IASP; 2010.

52. Peabody JW. Improving the quality of care in developing countries. In: Disease control priorities in developing countries. 2nd edn. New York: Oxford University Press; 2006. p. 1293-307. 